\title{
Concepções em pesquisa social: articulações com o campo da avaliação em serviços de saúde
}

\author{
Concepts in social research: links with the field \\ of health services evaluation
}

Suely Ferreira Deslandes 1

1 Centro Latino-Americano de Estudos sobreViolência e Saúde "Jorge Careli", Fundação Oswaldo Cruz Av. Brasil 4036, sala 702, Rio de Janeiro, RJ, Brasil.
Abstract This paper discusses theories and research perspectives from the social sciences and their role in constituting the field of "health services eval uation". The objective is to present less explored theoretical fields such as the "comprehensive" and "dialectical" approaches. Finally, the study presents a methodological proposal based on a qualitative approach to the evaluation of health services and projects.

Key words Health Evaluation; Health Services; Social Sciences Research; Qualitative Methodology

Resumo O presente texto discute a participação das matrizes teóri cas e concepções de pesqui sa das Ciênci as Sociais no campo da "avali ação de servi ços de saúde". Pretende-se apontar possí veis campos teóri cos pouco expl orados pela área de "avaliação de serviços", tais como as propostas "compreensivas" e "dialéti cas". Final mente o artigo apresenta uma proposta de metodologi a qualitativa para a avaliação de serviços e projetos de saúde.

Palavras-chave Avaliação em Saúde; Serviços de Saúde; Pesquisa Social; Metodologia Qualitativa 


\section{Introdução}

A avaliação de programas e serviços se faz presente em várias áreas: Educação, Administração, Economia, Serviço Social e Saúde Pública. Em cada campo temático em que se insere, o escopo da avaliação ganha contornos próprios que se materializam sob a forma de conceitos específicos, indicadores e técnicas apropriadas de aplicação.

A avaliação de serviços também se caracteriza por lançar mão de teorias e metodologias diversas, sobretudo aquelas oriundas das Ciências Sociais. Contudo, a avaliação de serviços, em sua prática institucional, reifica sua dimensão técnica e de operatividade de tal forma que, apesar de serem etapas fundamentais, obscurecem a discussão teórico-metodológica sobre o assunto. Este movimento não deixa de causar um certo empobrecimento e dogmatismo, pois reduz um amplo campo de produção de conhecimento à sua instância técnica. Este reducionismo se torna criticável, uma vez que o conhecimento da pesquisa avaliativa tem a peculiaridade de ser estratégico e viabilizador de uma práxis social. Agindo assim, mistificam a técnica, revestindo-a de uma objetividade que se pretende indiscutível. Desta maneira, é desfocada a vinculação da dimensão técnica com as escolhas teóricas e metodológicas que as embasam e as precedem. É esquecida a máxima epistemológica de que qualquer técnica é uma teoria em ato.

No campo da Saúde Pública, a avaliação de serviços é área de extrema relevância, já que viabiliza escolhas de planejamento e possibilita um controle técnico e social dos serviços e programas prestados à sociedade. Entretanto, também aí se verifica a vivência das questões acima descritas.

O presente artigo visa discutir, em nível introdutório, sobre campos teóricos pouco explorados pela área de "avaliação de serviços", tais como as propostas "compreensivas" e "dialéticas" que, a nosso entender, podem constituir importante eixo de orientação às avaliações de serviços de saúde. Neste sentido, o texto tem como objetivo fundamental propor algumas bases para uma metodologia qualitativa de avaliação de serviços que ven ha contribuir e complementar as propostas já consagradas neste campo.
Avaliação de serviços:

novas abordagens

A avaliação de serviços de saúde é uma área já consolidada em suas várias linhas de abordagens. A utilização de indicadores de avaliação econômica, tecnológica e de qualidade da atenção em saúde (acesso, utilização, cobertura, eficácia, satisfação do usuário, objetivos, estrutura, processos, resultados, entre outros) é hoje reconhecida e amplamente divulgada. Este campo de conhecimento denominado "avaliação de serviços", apesar de dispor de várias linhas de pesquisa (OPS, 1992), tem suas matrizes teóricas oriundas de outras áreas do conhecimento. Como afirmam Aguilar e Ander-Egg (1994:23), “a pesquisa avaliativa não possui métodos e técnicas próprios; ela utiliza os mesmos métodos e técnicas da pesquisa social".

O paradigma positivista, outrora hegemônico nesse campo, passa a ser questionado por diversos pensadores, que apontam a subjetividade inerente a qualquer avaliação. A pretensa objetividade passa a ser percebida como limitada pelos vários recortes produzidos pelo investigador. Decisões que dizem respeito a quais informações devem ser coletadas, escoIha da amostra, seleção de critérios e princípios, métodos de tratamento estatístico, passam a ser percebidos como envolvendo julgamentos de valor (Holland, 1983).

As concepções mais atuais de avaliação incorporam ao conceito de serviço de saúde a questão dos movimentos sociais e o conceito de Estado ampliado. Nesta perspectiva, o serviço é pensado como um campo de práticas técnicas, sociais e políticas, cuja direção e agenda de prioridades são realizadas no campo dos embates políticos entre grupos de pressão politicamente competentes e de racionalidades distintas (técnica e política) (Cohen \& Franco, 1993).

É possível afirmar que a avaliação de serviços de saúde ao longo dos últimos anos deixou de ser considerada um processo exclusivamente técnico, um método que, dispondo de um conjunto de procedimentos e indicadores, poderia medir com presteza a efetividade de determinado serviço ou programa.

O estudo das representações sociais em saúde e da antropologia médica vieram mostrar que o processo saúde/ doença é permeado de elementos culturais, sociais e econômicos, sendo compreendido e vivenciado diferentemente pelos vários atores que dele participam. Assim, o sucesso ou não de determinado serviço ou programa estaria também ligado à correspondência a determinados valores, ideolo- 
gias, posições de classe, status, etnia, crenças de seus usuários, comunidade e agentes. A avaliação, portanto, levaria em conta a análise crítica de se determinado serviço se coadunaria ou não aos valores culturais e expectativas dos vários atores sociais envolvidos, assim como às suas realidades sócio-econômicas (Atkinson, 1993).

Um exemplo conhecido nesta linha de abordagem é o método RAP (Rapid Assessment Procedures). O RAP consiste numa proposta de método rápido de estudo e avaliação de programas que foi desenvolvido na década de 80 , já tendo sido testado em mais de 23 países (Scrimshaw \& Hurtado, 1987). Trata-se, na realidade, de uma simplificação do método antropológico, aplicando-o aos problemas, ações e programas de saúde. A premissa básica do RAP é de que cada ação de saúde deve ser instaurada ou organizada contemplando as distintas expectativas sociais que giram ao seu redor. $\mathrm{O}$ método fundamenta-se na premissa de que é preciso articular informações estatísticas sobre determinada demanda de ação em saúde com o significado destes fatos para os sujeitos sociais que os vivenciam (comunidade, grupos e profissionais de saúde). O principal problema do RAP, como já apontado por Coimbra Jr. (1993), é a redução do método antropológico à aplicação de técnicas de pesquisa, dissociando-se as teorias que as fundamentam. $O$ autor questiona também a pertinência da análise a ser realizada uma vez que será conduzida por leigos.

O RAP é uma das propostas desta articulação, ainda pioneira, do campo de avaliação de serviços com as perspectivas compreensivas de análise.

No final dos anos 80, a supremacia dos dados quantitativos como suporte único para a avaliação passou a ser revista. As análises provenientes das Ciências Sociais ganham maior visibilidade (10 Congresso Brasileiro de Ciências Sociais em Saúde, 1995). A visão qualitativa vem contribuir ao foro de debates, numa visão de complementaridade e de enriquecimento do arsenal teórico-metodológico da avaliação em saúde.

Nesta linha, um programa ou serviço é entendido como um processo que possui movimento, uma dinâmica própria. É levada em conta a ação de atores distintos que se aliam e se contrapõem, trata-se de uma busca hermenêutica por compreender antagonismos e consensos. Desta forma, avaliar é também decodificar conflitos visando ao entendimento da cultura institucional e da prática dos agentes que o serviço ou programa envolve. Trata-se tam- bém de analisar, dialeticamente, os movimentos sociais e a conjuntura histórica de que o serviço/ programa participa, seja como portavoz, interlocutor ou personagem de resistência.

A perspectiva dialética nos indica que a análise da história destes serviços e projetos, suas especificidades, sua interação com outros atores institucionais, a capacidade participativa de seus membros e a correlação entre os aspectos micro e macropolíticos e econômicos devem ser itens contemplados em toda análise avaliativa (Demo, 1991).

A perspectiva compreensiva lança algumas balizas, indicando que os sujeitos sociais estabelecem, ao longo de sua existência social, significados, intencionalidades e teorias explicativas sobre o mundo e as estruturas sociais. Desta forma, o pesquisador, ainda que revestido do método científico, não é o único que produz explicações e análises dos fatos sociais (Minayo, 1992). As análises dos sujeitos sociais envolvidos nos serviços/ programas sobre estas experiências não podem ser ignoradas, mas reconhecidas como portadoras de racionalidade e analisadas sob a luz das conexões históricosociais que conformam tais discursos. A análise de serviços envolve também a análise da "consciência histórica" de seus agentes e de suas representações sociais, que por sua vez estarão objetivadas em suas práticas.

\section{Construindo uma proposta de metodologia qualitativa para avaliação de serviços e ações em saúde}

O esforço aqui empreendido se faz no sentido de traçar as bases preliminares para a operacionalização de uma proposta de metodologia qualitativa de avaliação de serviços, projetos e ações de saúde.

Segundo a perspectiva dialética, a análise de uma ação institucional não pode prescindir da compreensão das contradições presentes naquela ação, pois incorreria ao erro de negarIhe seu caráter histórico e dinâmico. Entendese que o real (aqui delimitado como as relações sociais em saúde) é móvel, múltiplo, diverso e contraditório. No movimento dialético de investigação, o conceito de contradição desempenha papel crucial, pois não se trata de uma oposição excludente entre o "sim" ou o "não", mas uma relação com profundas vinculações no concreto, que se apresenta sob termos que se negam ativamente, mas que se interpenetram e criam algo novo. O princípio de identidade dialética é, por definição, uma "unidade 
das contradições". Assim, todo ser é um devir, é um vir-a-ser (Lefebvre, 1979).

Mas como operacionalizar uma proposta de investigação situada num campo da análise organizacional (análise dialética das organizações) tão pouco explorado para o campo da avaliação em saúde?

Percebe-se a importância da análise das estruturas e do funcionamento organizacional como instrumentos importantes para a compreensão do "movimento histórico" do serviço. Contudo, deve-se notar que a estrutura e funcionamento não são realidades formais, mas frutos de atividade objetivada dos atores envolvidos e que, portanto, este movimento é permeado por contradições que devem ser analisadas.

A unidade para análise é a totalidade que o serviço representa. Vale destacar que, a análise dialética, ao lançar mão do conceito de totalidade, preocupa-se em não se restringir somente à descrição das condições, fatores ou mecanismos que interferem na produção daquele fenômeno ou processo social, mas analisar as conexões existentes entre os elementos que o determinam.

Afirma-se, portanto, enquanto unidade de análise, não o serviço "em si", mas a "atuação do serviço", que corresponde à rede de relações internas e externas (interação com outros atores sociais), vivências, estruturas e processos que constituem aquela prática institucional. A categoria "atuação do serviço" retém não somente a base empírica das ações (registro de casos, atendimentos, procedimentos efetuados, caracterização da população-alvo e outras atividades), como também contempla as relações que fundam a estrutura do serviço, seus processos e ainda inclui o conjunto de representações articuladas pelos atores sociais sobre esta ação.

Finalmente, propõe-se, para melhor compreensão da proposta, que a análise seja dividida em etapas. Estas, apesar de constituírem momentos distintos da análise, correspondem a elementos de uma realidade integrada.

A primeira etapa constitui-se na caracterização detalhada do que emerge do conjunto de dados empíricos, como o primeiro nível da atuação do serviço. Em outras palavras, esta etapa busca descrever pormenorizadamente o nível empírico. Neste primeiro momento, a atuação é entendida basicamente como o "atendimento". Assim, a análise dedica-se a caracterizar o perfil da população atendida e os dados sobre a atuação do serviço. Os principais itens capazes de mapear o mais exaustivamente possível a "atuação" devem ser minuciosa- mente descritos. Esta primeira etapa já traz indicações das relações mais complexas presentes. Já aponta para as relações estruturais e os processos embutidos nesta "atuação", como também acena para algumas das contradições nela vivenciadas.

Na segunda etapa, busca-se compreender as relações que alicerçam e constituem a atuação daquele serviço ou programa. Estas se relacionam à estrutura do serviço, tais como: organização formal, definição de objetivos organizacionais, estrutura hierárquica, "mecanismos" de auto-preservação (alocação de recursos, recrutamento e treinamento de novos membros). Esta estrutura é fruto da ação dos vários atores sociais envolvidos na atuação e, portanto, é vista como uma ação historicamente condicionada.

Estas relações constituintes e constituídas na atuação do serviço também dizem respeito aos processos vivenciados. Quais processos deveriam ser analisados? A princípio, seria o próprio processo de trabalho, que culmina nas ações realizadas pelo serviço. Outro processo importante para a compreensão da "atuação " é o contexto das interações estabelecidas entre os diversos atores sociais envolvidos nas atividades (agentes, população-alvo, secretarias de governo, outras instituições).

E por fim, lançando mão da perspectiva "compreensiva", busca-se perceber as representações articuladas sobre a atuação. Estas representações são testemunhos preciosos dos valores e práticas presentes na ação dos atores sociais, como também indicam os conflitos presentes na atuação.

Na terceira etapa, analisam-se as principais contradições existentes na "atuação". Mas a que tipo de contradições refere-se este trabaIho? Aquelas que correspondem aos hiatos entre o discurso e a prática do serviço sem dúvida devem ser apontadas. Contudo, as contradições estruturais devem ser o alvo da análise, ou seja, aquel as que estão vinculadas aos processos sociais mais amplos e que perpassam a atuação do serviço (políticas públicas de saúde, políticas econômicas, movimentos sociais relacionados).

Sintetizando mais esquematicamente, a metodologia proposta realiza-se através das seguintes fases:

1) Conhecimento aprofundado da atuação (serviço ou ação) que se pretende analisar. Esta fase, eminentemente descritiva, busca conhecer: os principais objetivos institucionais, os dados estatísticos já produzidos pelo próprio serviço, secretarias e outras instituições de pesquisa, estratégi as e dinâmica de atendimento, ca- 
racterísticas da população-alvo, capacidade de cobertura e utilização, recursos utilizados. Enfim, todas as informações disponíveis devem ser pesquisadas. Esta fase, como já dito, além de caracterização também possibilita ao pesquisador a percepção inicial das contradições e antagonismos existentes, assim como o habilita a postular novos problemas à sua investigação.

2) Análise da correlação existente entre o projeto institucional daquele serviço ou ação ao quadro mais amplo das políticas públicas que o justifique ou contextualize. Esta fase busca analisar, em nível estrutural, as racionalidades técnicas e políticas que sustentam o projeto, bem como as contradições que vivencia.

3) Conhecimento empírico da atuação que se avalia. Esta fase é a de trabalho de campo. Busca-se conhecer o dia-a-dia do serviço ou da ação de saúde. Defendemos que nada substitui esta experiência na qual o pesquisador terá a oportunidade de observar a ação concreta dos atores envolvidos, os problemas vivenciados, os antagonismos latentes e o relacionamento entre os sujeitos sociais implicados.

4) Análise das representações sociais dos atores sociais (clientela, profissionais do serviço, gerentes, planejadores, serviços de contra-referência ou apoio). Esta fase é um desdobramento da fase anterior. Busca-se compreender os valores, opiniões e "visões de mundo" acerca do serviço/ prática que se quer avaliar. Entende-se que a tarefa de compreensão das expectativas sociais, aspectos culturais e ideológicos dos atores diretamente envolvidos com a prática institucional é crucial para analisar os "nós górdios", as possi bilidades de sucesso e os pontos de (não) adesão e resistência.

5) Análise propriamente dita. Esta etapa de confecção do relatório/diagnóstico encaminha-se na perspectiva da pesquisa estratégica. Isto é, busca-se articular conhecimentos teóricos sobre a temática à qual refere-se a avaliação de problemas empíricos visando propor ações (técnicas/ políticas). Outra perspectiva importante é o compromisso de compartilhar um conhecimento produzido com aqueles sujeitos sociais cujas ações e vivências foram objeto de reflexão.

A metodologia que se propõe é, sem dúvida, uma aplicação do método das Ciências Sociais; contudo, o objeto que se avalia (processos e práticas em saúde) situa-se num campo interdisciplinar por definição. A avaliação, portanto, deve ser vista como este desafio de articulação entre as distintas disciplinas que constituem a Saúde Pública. Por outro Iado, também demarca um espaço concreto de contribuição do cientista social ao campo da avaliação de serviços e projetos de saúde.

\section{Referências}

AGUILAR, J. M. \& ANDER-EGG, E., 1994. Avaliação de Serviços e Programas Sociais. Petrópolis: Vozes.

ATKINSON, J., 1993. Anthropology in Research on the Quality of Health service. Cadernos de Saúde Pública, 9:283-299.

COIMBRA JR, C. E. A., 1993. Resenha. Cadernos de Saúde Pública, 9:398-400.

COHEN, E. \& FRANCO, R., 1993. Avaliação de Projetos Sociais. Petrópolis: Vozes.

10 CONGRESSO BRASILEIRO DE CIÊNCIAS SOCIAIS EM SAÚDE, 1995. Mesa Redonda “Avaliação de Políticas eServiços deSaúde: O Olhar das Ciências Sociais". Curitiba.

DEM O, P., 1991. Avaliação Qualitativa. São Paulo: Cortez (Coleção Polêmicas de Nosso Tempo, v.25).
HOLLAND, W. W., 1983. Evaluation of Health Care. Norfolk: Oxford University Press.

LEFEBVRE, H., 1979. Lógica Formal. Lógica Dialética. Rio de Janeiro: Civilização Brasileira.

MINAYO, M. C. S., 1992. O Desafio do Conhecimento. São Paulo/ Rio de Janeiro: Hucitec/ Abrasco.

OPS (Organización Panamericana de la Salud), 1992. Investigaciones sobre Servicios de Salud: Una Antología. OPS. Publicación Científica, n.534.

SCRIM SHAW \& HURTADO, 1987. Rapid Assessment Procedures for Nutrition and Primary Health Care. UCLA Latin American Center Publications., v.11. 